\title{
Fabrication of scalable tissue engineering scaffolds with dual-pore microarchitecture by combining 3D printing and particle leaching
}

Mohanty, Soumyaranjan; Kuldeep, Kuldeep; Heiskanen, Arto; Trifol Guzman, Jon; Szabo, Peter; Dufva, Martin; Emnéus, Jenny; Wolff, Anders

Published in:

Materials Science and Engineering C: Materials for Biological Applications

Link to article, DOI:

10.1016/j.msec.2015.12.032

Publication date:

2016

Document Version

Publisher's PDF, also known as Version of record

Link back to DTU Orbit

Citation (APA):

Mohanty, S., Kuldeep, K., Heiskanen, A., Trifol Guzman, J., Szabo, P., Dufva, M., Emnéus, J., \& Wolff, A.

(2016). Fabrication of scalable tissue engineering scaffolds with dual-pore microarchitecture by combining 3D printing and particle leaching. Materials Science and Engineering C: Materials for Biological Applications, 61, 180-189. https://doi.org/10.1016/j.msec.2015.12.032

\section{General rights}

Copyright and moral rights for the publications made accessible in the public portal are retained by the authors and/or other copyright owners and it is a condition of accessing publications that users recognise and abide by the legal requirements associated with these rights.

- Users may download and print one copy of any publication from the public portal for the purpose of private study or research.

- You may not further distribute the material or use it for any profit-making activity or commercial gain

- You may freely distribute the URL identifying the publication in the public portal 


\title{
Fabrication of scalable tissue engineering scaffolds with dual-pore microarchitecture by combining 3D printing and particle leaching
}

\author{
Soumyaranjan Mohanty ${ }^{\text {a }}$, Kuldeep Sanger ${ }^{\text {a }}$, Arto Heiskanen ${ }^{\text {a }}$, Jon Trifol ${ }^{\text {b }}$, Peter Szabo ${ }^{\text {, }}$, Marin Dufva ${ }^{\text {a }}$, \\ Jenny Emnéus ${ }^{a}$, Anders Wolff ${ }^{\mathrm{a}, *}$
}

a DTU Nanotech, Department of Micro- and Nanotechnology, Technical University of Denmark, Ørsteds Plads, DK-2800 Kgs. Lyngby, Denmark

b Danish Polymer Centre, Department of Chemical and Biochemical Engineering, Søltofts Plads, Building 229, DK-2800 Kgs. Lyngby, Denmark

\section{A R T I C L E I N F O}

\section{Article history:}

Received 13 October 2015

Received in revised form 27 November 2015

Accepted 14 December 2015

Available online 19 December 2015

\section{Keywords:}

Tissue engineering

3D printing

Salt leaching

Scaffolds

Structured pores

Random pores

Dual pores

\begin{abstract}
A B S T R A C T
Limitations in controlling scaffold architecture using traditional fabrication techniques are a problem when constructing engineered tissues/organs. Recently, integration of two pore architectures to generate dual-pore scaffolds with tailored physical properties has attracted wide attention in tissue engineering community. Such scaffolds features primary structured pores which can efficiently enhance nutrient/oxygen supply to the surrounding, in combination with secondary random pores, which give high surface area for cell adhesion and proliferation. Here, we present a new technique to fabricate dual-pore scaffolds for various tissue engineering applications where 3D printing of poly(vinyl alcohol) (PVA) mould is combined with salt leaching process. In this technique the sacrificial PVA mould, determining the structured pore architecture, was filled with salt crystals to define the random pore regions of the scaffold. After crosslinking the casted polymer the combined PVA-salt mould was dissolved in water. The technique has advantages over previously reported ones, such as automated assembly of the sacrificial mould, and precise control over pore architecture/dimensions by 3D printing parameters. In this study, polydimethylsiloxane and biodegradable poly( $\epsilon$-caprolactone) were used for fabrication. However, we show that this technique is also suitable for other biocompatible/biodegradable polymers. Various physical and mechanical properties of the dual-pore scaffolds were compared with control scaffolds with either only structured or only random pores, fabricated using previously reported methods. The fabricated dual-pore scaffolds supported high cell density, due to the random pores, in combination with uniform cell distribution throughout the scaffold, and higher cell proliferation and viability due to efficient nutrient/oxygen transport through the structured pores. In conclusion, the described fabrication technique is rapid, inexpensive, scalable, and compatible with different polymers, making it suitable for engineering various large scale organs/tissues.
\end{abstract}

(C) 2015 Published by Elsevier B.V.

\section{Introduction}

In recent years, there has been a significant medical demand for the development of a functional engineered tissue constructs suitable for tissue/organ replacement. One of the primary challenges in translation of tissue engineering for clinical applications is the difficulty in scaling up complex, biologically effective tissues and organs to the size adequate for human therapy [1]. Generation of a thick 3D tissue requires development of highly dense vascular networks that can meet the nutrient and oxygen requirements of a bulk tissue composed of a large quantity of living cells [2]. Blood vessel formation within the bulk tissue construct does not occur within a sufficient time frame to supply the necessary

\footnotetext{
* Corresponding author at: BioLabchip group, Department of Micro- and Nanotechnology, Technical University of Denmark, Building 423, Ørsteds Plads, Kgs. Lyngby DK-2800, Denmark.
}

E-mail address: anders.wolff@nanotech.dtu.dk (A. Wolff). amount of nutrients and oxygen, leading to necrosis in the formed tissue [3]. Therefore, there is a great demand for a smart scaffold designs for effective and efficient nutrient and oxygen transport throughout the bulk of thick engineered tissues.

Polymeric tissue engineering scaffolds with disordered or random micropores have traditionally been fabricated using various techniques, such as particle leaching, phase separation, and gas foaming [4-6]. Even though these techniques are scalable and economical, they do not allow accurate control of the scaffold microenvironment, determined by the pore architecture, mechanical strength, surface area and mass transport within the scaffold [7]. These techniques can only generate one type of pore geometry i.e. local/random in the scaffold. It has been shown that scaffolds consisting of only random pores can significantly limit cell penetration and uniformity of the cell distribution due to limited diffusion of culture medium into the centre of the scaffolds [8-10]. Therefore, there is a need for a second type of porous structure, which can efficiently interconnects local random pores of the scaffold for better generation of large tissues under in vitro and in vivo conditions. 
Recently, studies using dual-pore scaffolds, comprising structured pores (channels) in combination with local random porous regions, have shown tremendous potential towards engineering of complex tissues with better cell proliferation due to improved nutrient and oxygen transport [3,11-16]. A recent report also demonstrated that after transplantation of dual-porous scaffolds more cells from the host tissue infiltrated into the scaffolds due to its smart global pore architecture compared to random porous scaffolds, hence, enhancing integration of blood vessels in the host tissue [17]. The structured pores help overcome the diffusion limitation while the random pores provide a large surface area to accommodate a high density of cells. Therefore, dual-pore scaffold design with perfusable channels serves as a promising strategy for engineering of large-scale artificial tissues or organs for regenerative medicine by promoting rapid vascularization that enhances survival of the seeded cells.

Different approaches have been employed to fabricate dual-pore scaffolds for tissue engineering using both natural and synthetic polymers $[3,11-15,18,19]$. For controlling the size and degree of porosity of the random pores as well as the mechanical properties of the scaffolds, the two major fabrication techniques have been freeze-drying $[3,11,13,14$, $20]$ and salt leaching $[11,12,16]$ process. The published results have shown that freeze-drying cannot yield as large a range of pore dimensions as salt leaching, which can utilize salt crystals of various dimensions depending on the requirements. Currently various solid freeform (SFF) fabrication techniques such as stereolithography based printing have been reported to fabricate 3D porous scaffolds with well controlled pore size, porosity and mechanical properties using photo-crosslinkable materials [21,22]. Sacrificial moulds from SFF fabrication [11] or metallic wires $[3,12,16,19]$ have been implemented for the generation of structured pores. Automated SFF fabricated moulds have several advantages compared to metal wire based moulds that require choice of wire dimensions and time consuming manual assembly of a number of wires. Hence, SFF based moulds are more reliable and rapid to use as well as provide easy upscaling of scaffold size. However, the SFF techniques presented by Kang et al. [11] required manual assembly of different stereolithographic printer parts and synthesis of photo curable inks for fabrication of the sacrificial mould. Moreover, fabrication of sacrificial moulds using stereolithography is a slow and expensive process requiring expensive commercial 3D printing equipment. Hence, there is an urgent need to develop SFF moulds using inexpensive 3D printing.

Recently, 3D printed poly(vinyl alcohol) (PVA) sacrificial moulds using 3D filament printer have been demonstrated to facilitate fabrication of porous polymeric scaffolds for various tissue engineering applications $[23,24]$. Ortega et al. and Jeffries et al. have proposed a new fabrication approach by encapsulating 3D printed single layered PVA channels using an inexpensive 3D filament printer in combination with electrospun nanofibers to create perfusable vascular networks $[23,24]$. However, the fabricated scaffolds only comprised a single layer of channels, hence, they didn't generate a functional tissue/organ composed of multiple layers. Moreover, the random pores had dimensions of only a few nanometres, and were thus not able to facilitate cell penetration into the interior of the scaffolds. There is therefore a need to develop a new approach to fabricate multi-layered dual-pore scaffolds using a sacrificial mould that allows precise control over the geometry and dimensions of the structured and random pores.

In this paper, we present a new method for fabrication of dual-porous scaffolds using the combination of 3D filament printing and salt leaching process to control the geometry and dimensions of the structured and random pores, respectively. The 3D printing of a sacrificial PVA mould allows generation of structured pores with a high degree of control over the inner architecture designed according to the requirements of an application as we have described previously [25]. The parameters of the random pores, e.g., degree of porosity and pore size, are controlled by varying the size of the salt crystals used as the porogen. After casting the desired polymer in the mould and cross-linking it the PVA and salt are dissolved, leaving behind a dual-pore scaffold. The fabrication process is scalable and capable of generating scaffolds that are structurally and dimensionally relevant for tissue engineering applications. We show the fabrication using polydimethylsiloxane (PDMS) and cultured human hepatoblastoma (HepG2) cells for 16 days to demonstrate that the scaffolds could provide 3D microenvironment able to support cell growth and liver tissue functionality. The performance of the dual-pore scaffolds is compared with scaffolds having either only structured or only random pores fabricated using 3D printed PVA moulds or salt leaching, respectively.

\section{Materials and method}

\subsection{Mould fabrication}

Sacrificial moulds for both structured and dual-pore scaffolds were 3D printed using a Replicator 2X 3D filament deposition printer (MakerBot Industries, LLC, Brooklyn, NY, USA) as described previously [25]. In brief, a 3D cube ( $25 \mathrm{~mm} \times \mathrm{W} 25 \mathrm{~mm} \times \mathrm{H} 10 \mathrm{~mm}$ ) was designed using SolidWorks 2013 3D CAD design software (Dassault Systems, SolidWorks Corp., Waltham, MA, USA). The design was exported as STL format into the 3D printing software (Makerware 2.4.1) for G-code generation and mould printing. Water dissolvable poly(vinyl alcohol) (PVA) filaments (MakerBot, USA) were used to print the sacrificial moulds. The printing was performed at $200{ }^{\circ} \mathrm{C}$ as the nozzle temperature and $40^{\circ} \mathrm{C}$ as the bed temperature. The PVA moulds printed with various porosities (infills) were used directly for fabrication of the structured pore scaffolds. For fabrication of the dual pore scaffolds (shown in Fig. 1 and summarised in Fig. S6), the PVA moulds were printed with $40 \%$ infill as shown in Fig. $1 \mathrm{~A} .10 \mathrm{~g}$ of $\mathrm{NaCl}$ (Sigma-Aldrich Corporation, St. Louis, MO, USA) crystals (size 300-600 um) was mixed with $1 \mathrm{ml}$ of ultrapure water from a Milli-Q® water purification system (Millipore Corporation, Billerica, MA, USA) and packed manually into the PVA mould (Fig. 1B). The salt filled moulds were dried in an oven at $60{ }^{\circ} \mathrm{C}$ for $1 \mathrm{~h}$. The small amount of water was used to form the interconnections between the salt crystals as well as between the salt crystals and PVA filaments.

Both the PVA moulds for the structured pore scaffolds and the salt-PVA moulds for the dual-pore scaffolds were replicated into polydimethylsiloxane (PDMS) (Sylgard 184 Elastomer kit, Dow Corning Corporation, Midland, MI, USA). The PDMS base was mixed thoroughly with the curing agent in a 10:1 ratio and the mixture was degassed in a vacuum desiccator to remove air bubbles. The PDMS mixture was then cast into the mould (Fig. 1C). Then, the container with the mould covered with PDMS mixture was transferred into the vacuum desiccator for 2-3 h to ensure complete infiltration of PDMS into the mould (Fig. 1D). The PDMS was cured at $60{ }^{\circ} \mathrm{C}$ in an oven for 4-6 h. After curing, the excess PDMS around the moulds was removed to expose the PVA or salt-PVA structures. This was done to allow the subsequent dissolution of PVA and salt in water. The entire mould-PDMS structures were immersed into water (Fig. 1E) until the PVA and salt had been completely removed (about 6-12 h), releasing the PDMS scaffolds with structured pore or dual-pore architecture (Fig. 1F).

The random pore scaffolds were fabricated using salt leaching process as described previously $[9,12] .10 \mathrm{~g}$ of $\mathrm{NaCl}$ was mixed with $1 \mathrm{ml}$ of water on a $100 \mathrm{~mm}$ plastic petri plate as described above. The mixture was placed in an oven at $60{ }^{\circ} \mathrm{C}$ to generate interconnections between the salt crystals and to evaporate the excess water. The hardened salt cube was cooled at room temperature. The PDMS mixture prepared as described above and cast on the petri plate containing the salt cube. The PDMS covered salt cube was placed in a vacuum desiccator for $1 \mathrm{~h}$ to let the PDMS infiltrate into the pores of the salt cube. The PDMS was cured in an oven at $60{ }^{\circ} \mathrm{C}$ for $4-6 \mathrm{~h}$. Finally, excess PDMS was removed and the salt was dissolved in water, as described above, to release the random porous PDMS scaffolds. 


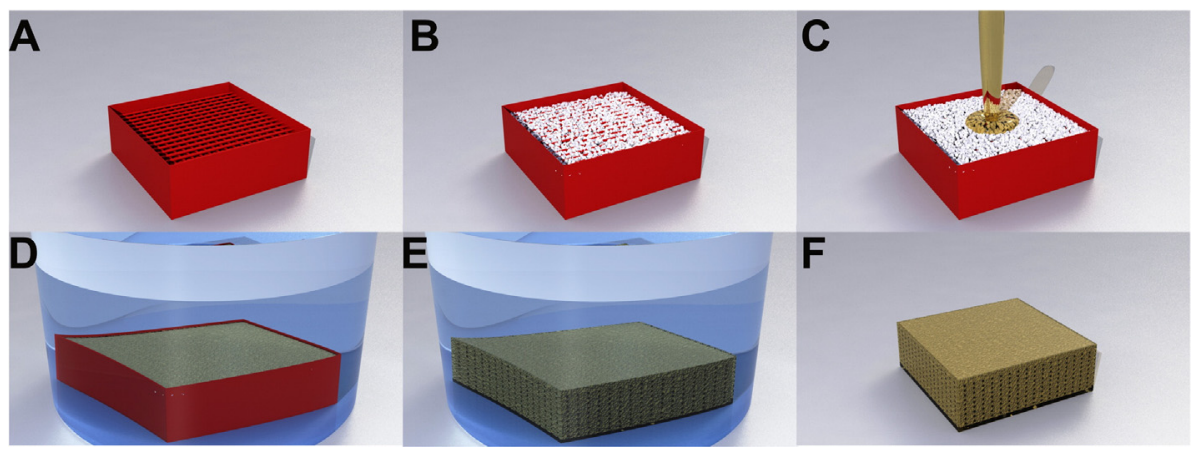

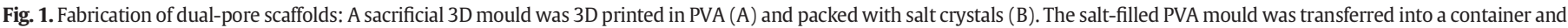

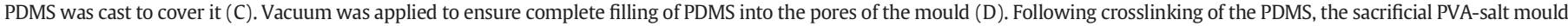
was dissolved in water (E) releasing the dual-pore PDMS scaffold (F).

\subsection{Characterizations of scaffolds}

The structural morphology and microstructures of the porous scaffolds were imaged using scanning electron microscopy (SEM) (JEOL, JSM 5500 LV, Tokyo, Japan). Prior to SEM imaging, the dried scaffolds were sputter coated with gold. The imaging was done using $12 \mathrm{kV}$ accelerating voltage. To evaluate the complete removal of sacrificial moulding materials from the scaffolds, Fourier transform infrared (FTIR) spectroscopic characterization of the moulding materials (salt and PVA) as well as the surfaces of the structured and dual-pore PDMS scaffolds (cross-sectional surfaces after cutting the scaffolds, as shown in the Supplementary material Fig. S1) was performed using a spectrometer (Spectrum 100, Perkin Elmer Technologies, and Waltham, MA, USA) in transmission mode. The FTIR spectra of the samples were recorded by 20 scans in the range of $400-4000 \mathrm{~cm}^{-1}$ at a resolution of $2 \mathrm{~cm}^{-1}$ using air as background.

The porosity of the PDMS scaffolds was determined using Eq. 1 as described previously $[12,16]$. Four cylindrical scaffolds with structured, random and dual-pore architecture (Ø $6 \mathrm{~mm}$, height $6 \mathrm{~mm}$ ) were dried overnight at $60{ }^{\circ} \mathrm{C}$, and weighed to obtain the mass of the samples. The porosity was then calculated based on the weight and the dimensions using Eq. 1.

Porosity $(\%)=\frac{\mathrm{V}-\left(\frac{\mathrm{M}}{\rho}\right)}{\mathrm{V}} \times 100 \%$

where $\mathrm{V}$ is the volume of the scaffold, calculated based on its outer dimensions, $\mathrm{M}$ is the mass of the scaffold, and $\rho$ is the density of PDMS $\left(0.965 \mathrm{~g} / \mathrm{cm}^{3}\right)$.

The compressive modulus of different scaffolds ( $\mathrm{L} 25 \mathrm{~mm} \times \mathrm{W}$ $25 \mathrm{~mm} \times \mathrm{H} 10 \mathrm{~mm}$ ) was determined by uniaxial compression tests using an Instron ${ }^{\circledR}$ Tensile Tester 4301 (Instron Corporation, Norwood, MA, USA). The samples were compressed at a rate of $0.5 \mathrm{~mm} \mathrm{~min}^{-1}$. The compressive modulus was calculated as the slope of stress-strain curve from the linear range of the curve for each sample. The values reported were an average from testing of four independent scaffold of each type of porous scaffolds.

To assess wettability of the scaffolds, contact angle measurements were carried out on scaffolds before and after oxygen plasma treatment. The contact angle was measured optically using an OCA 20 system (Dataphysics, Germany) by the sessile drop method by depositing a $3 \mu \mathrm{l}$ drop of ultrapure water on the scaffold surface.

\subsection{Cell culture and assays in scaffolds}

\subsubsection{Cells}

Human hepatoblastoma (HepG2) cells were obtained from the German Collection of Microorganisms and Cell cultures (DMSZ,
Braunschweig, Germany). Cells were maintained in Roswell Park Memorial Institute medium (RPMI-1640) containing L-glutamine and supplemented with $10 \%$ foetal bovine serum (FBS), both from SigmaAldrich Corporation, St. Louis, MO, USA, and 1\% penicillin/streptomycin (Life Technologies, Corporation, Paisley, UK) in a humidified incubator at $37{ }^{\circ} \mathrm{C}$ and $5 \% \mathrm{CO}_{2}$. Cell culture medium was exchanged completely every 2-3 days until the cells were fully confluent. The cells were detached from the culture flask using $0.025 \%$ trypsin/EDTA solution (Life Technologies, Corporation, UK) and the cell number was determined using a haemocytometer and adjusted to the required number before seeding into the 3D scaffolds.

\subsubsection{Preparation of scaffolds for cell culture}

The scaffolds were prepared according to the protocol published previously [25]. In brief, cylindrical PDMS scaffolds of each type ( $\varnothing$ $6 \mathrm{~mm}$, height $6 \mathrm{~mm}$ ) were used in the experiments. Here, for cell studies control scaffolds with only structured pores, $80 \%$ porosity were used. To render the PDMS hydrophilic, scaffolds were treated with oxygen plasma for $1 \mathrm{~min}$ on both sides at a power of $50 \mathrm{~W}$ and pressure of 35 Pa using an Atto Plasma System (Diener Electronic GmbH, Ebhausen, Germany) equipped with a $13.56 \mathrm{MHz}$ RF generator. The oxygen plasma treated scaffolds were autoclaved at $120^{\circ} \mathrm{C}$ for $20 \mathrm{~min}$ followed by coating with $80 \mu \mathrm{g} / \mathrm{ml}$ of Collagen I (Collagen I rat protein, Life Technologies) at $4{ }^{\circ} \mathrm{C}$ overnight. The scaffolds were washed twice with cell culture tested phosphate buffered saline (PBS) to remove excess collagen and then incubated in culture medium at $37^{\circ} \mathrm{C}$ for $2 \mathrm{~h}$ until cell seeding. The cells were seeded into the scaffolds using a special $6 \mathrm{~mm}$ thick cell seeding tray with several holes ( $66 \mathrm{~mm}$ ), fabricated of poly(methyl methacrylate) (PMMA) using a $\mathrm{CO}_{2}$ laser ablation machine (Epilog Mini 18 Laser, CO 80403, USA) as described previously [25]. The seeding tray was sterilized by washing with $0.5 \mathrm{M}$ sodium hydroxide solution followed by rinsing with sterile water. Each scaffold was inserted into the hole in the seeding tray. $30 \mu \mathrm{l}$ suspension of HepG2 cells in culture medium containing 250.000 cells was added on top of each scaffold and incubated at $37^{\circ} \mathrm{C}$ for $3 \mathrm{~h}$ to achieve cell attachment. Every hour the tray was turned upside down for better cell infiltration into the scaffolds. Finally, each scaffold was transferred from the seeding tray into a well in a 24-well plate, and $1 \mathrm{ml}$ of fresh culture medium was added in each well. Every 2 days the medium was collected for cellular functionality analysis and replaced with fresh medium. On day 4, 8 and 12 of the culture period, two scaffolds were sacrificed and used for live/dead staining. Similarly, for determination of the total cell number, three scaffolds of each type were sacrificed at each time point (day 2, 4, 6, 8, 12, and 16).

\subsubsection{Biochemical assays}

Cell proliferation was determined based on the DNA content of cells cultured in the scaffolds. The cells inside the scaffolds were lysed using $1 \mathrm{ml}$ of lysis buffer (10 mM Tris pH 8, $1 \mathrm{mM}$ EDTA and $0.2 \%$ (v/v) Triton $\mathrm{X}-100$ ). To ensure that the cells inside the scaffolds were totally lysed, 
the samples were stored on ice for $30 \mathrm{~min}$ and vortexed for $10 \mathrm{~s}$ every $5 \mathrm{~min}$. The lysate from each scaffold was homogenised 5-10 times using a 21-guage needle. The DNA concentration in the lysates was quantified using PicoGreen DNA assay (Life Technologies Corporation, UK) according to the manufacturer's protocol. A standard of DNA concentrations was prepared by isolating dsDNA from HepG2 cells (known number of cells) cultured in T25 flasks using the same protocol as for the scaffolds. The calibration curve was obtained by correlating the number of cells with the corresponding fluorescence intensity (shown in the Supplementary material Fig. S4).

The metabolic activity of the cells was measured using the alamarBlue ${ }^{\circledR}$ assay (Life Technologies Corporation, UK) as described previously [25]. In short, the scaffolds were rinsed with PBS and incubated in $1 \mathrm{ml}$ of culture medium containing $10 \%$ alamarBlue ${ }^{\circledR}$ solution for $2 \mathrm{~h}$ in the incubator. Following incubation, 100- $\mu$ l aliquots were placed into black 96 well plates and the fluorescence was quantified using a microplate reader (VICTOR3 ${ }^{\mathrm{TM}}$ Multilabel Counter model 1420, PerkinElmer, USA) at the excitation wavelength of $550 \mathrm{~nm}$ and emission wavelength of $590 \mathrm{~nm}$. The background (i.e. alamarBlue ${ }^{\circledR}$ fluorescence at day 1 ) was subtracted from the value.

The concentration of albumin secretion from the cells in the scaffolds was determined using human albumin enzyme-linked immunosorbent assay (ELISA) Quantitation kit (Bethyl Laboratories, Inc., Montgomery, AL, USA) according to the manufacturer's protocol. The absorbance was measured at $450 \mathrm{~nm}$ using a spectrophotometer (VICTOR3 ${ }^{\mathrm{TM}}$ Multilabel Counter model 1420, PerkinElmer, USA). For all the biochemical assays, the tests were carried out in triplicate using 3 independent scaffolds of each type. The results are reported as average \pm standard error of the mean (s.e.m) $(n=9)$.

\subsubsection{Live/dead cell staining}

Cell viability and distribution in the scaffolds were visualized using LIVE/DEAD® Cell Imaging Kit (Life Technologies Corporation, UK), containing a cell-permeable dye for staining live cells (excitation/emission $488 \mathrm{~nm} / 515 \mathrm{~nm}$ ) and a cell-impermeable dye for staining dead and dying cells (excitation/emission $570 \mathrm{~nm} / 602 \mathrm{~nm}$ ). The scaffolds were collected and gently washed with PBS followed by incubation in the dye solution for $30 \mathrm{~min}$ at $37^{\circ} \mathrm{C}$ according to the manufacturer's protocol. The scaffolds were imaged using an Axio Observer fluorescence microscope (Zeiss Axio Observer.Z1, Carl Zeiss, Germany). The 3D reconstructions were compiled from 20 imaged sections (each having a thickness of $30 \mu \mathrm{m})$.

\section{Results and discussion}

Previously engineered dual-pore scaffolds with highly interconnected global (structured) and local (random) pores fabricated of both natural and synthetic biomaterials have shown promising results with improved cell proliferation in vitro and enhanced integration into the host tissue upon transplantation $[3,12,17]$. However, they had significant limitations in terms of mass fabrication and scalability due to the necessary manual assembly of the sacrificial mould components, as well as control of the dimensions and number of structured pores introduced into the bulk scaffold. Thus, novel strategies can help develop mass fabrication of dual-pore scaffolds with control over physical and mechanical properties. With the goal of developing a simple, inexpensive and reproducible method for mass fabrication of dual-pore scaffolds with tuneable physical properties, we present a technique combining 3D filament printing of sacrificial moulds and salt leaching. Subsequently, to evaluate the dual-pore scaffolds in terms of physical properties and biological performance (cell loading, cell distribution and cellular functionality), two other types of scaffolds, i.e. the structured pore and random pore scaffolds were fabricated and used as controls.

\subsection{Scaffold fabrication}

3D filament printing is an inexpensive SFF technique that offers highly versatile approach to fabricate the sacrificial moulds, allowing to deposit PVA polymer layers with different geometries in the $\mathrm{x}$ and $\mathrm{y}$ directions, such as 'woodpile' or 'hexagonal' (as shown in the Supplementary material Fig. S2), that functions as vascular porous networks. As we have shown previously, PVA moulds could be fabricated with porosities in the range of $20-80 \%$ depending on the infill of the mould, which were shown to correspond to channel distances ranging from $78 \mu \mathrm{m}$ to $1482 \mu \mathrm{m}$ [25]. Aside from effective control over channel dimensions and geometry, 3D filament printing allows to scale up the fabrication of tissue engineering scaffolds. Hence, to generate structured pores for dual-pore scaffolds, 3D printing of PVA filaments was an obvious choice for our fabrication process presented here. In this work, $40 \%$ infill was used to fabricate the PVA moulds for the dual-pore scaffolds, resulting in inter-filament distance of $800-850 \mu \mathrm{m}$. Salt leaching as the source of random pores gives the possibility to control the pore sizes range by choosing the size distribution of the salt crystals to mimic the anatomical features of the tissues or organs required to be engineered [26]. In this study, the $\mathrm{NaCl}$ crystals were used directly as provided by the supplier, sizes ranging from $300 \mu \mathrm{m}$ to $600 \mu \mathrm{m}$.

The PDMS scaffolds with structured pores (Fig. 2Ab) were fabricated using 3D printed PVA filament moulds with woodpile pattern (Fig. 2Aa), while the random pore scaffolds (Fig. 2Bb) were derived from cylindrical salt disks (Fig. 2Ba) using previously described methods [22, $25,27]$. As shown in the SEM image of the structured pore scaffold in Fig. 2Ac, the pores are square shaped with dimension of $\sim 400 \mu \mathrm{m} \times$ $400 \mu \mathrm{m}$ and well interconnected. In the random pore scaffolds, the salt leaching process gives pores with dimensions in the range of 300$600 \mu \mathrm{m}$ (Fig. 2Bc), as determined by the size distribution of the used salt crystals.

By combining both approaches, we fabricated dual-pore scaffolds (Fig. $2 \mathrm{Cb}$ ) with both defined structured and random pore microarchitectures using the sacrificial 3D printed structured porous PVA filament moulds filled with salt crystals into the inter-filamentous space (Fig. 2Ca). The method of fabrication is simple and involves casting of the desired polymer (in this study PDMS was used) in the mould which specifies the microarchitecture of pores within the resulting scaffold. Surface top view of the dual-pore scaffold is shown in the SEM image (Fig. 2Cc). The structured pores of dimension $\sim 400 \mu \mathrm{m} \times 400 \mu \mathrm{m}$ are distributed in $\mathrm{x}, \mathrm{y}$ and $\mathrm{z}$ directions, whereas the random pores with dimension of $300-600 \mu \mathrm{m}$ are shown in between the structured pores of the bulk scaffold (Fig. 2Cc). As shown in the SEM image of the top surface of a dual-pore scaffold (Fig. 3A and its zoom-in view Fig. 3B), the scaffolds had regular, well-structured and highly interconnected structured pores in the $\mathrm{z}$ (yellow lines) and $\mathrm{x}-\mathrm{y}$ (red lines) direction throughout the scaffold. In between the structured pores, the scaffolds had an array of square shaped random porous regions of $800 \mu \mathrm{m} \times 800 \mu \mathrm{m}$. The salt crystals of size $300-600 \mu \mathrm{m}$ fused together and generated large interconnected pores. Fig. $3 \mathrm{C}$ and its zoom-in Fig. 3D, show SEM image of cross-sectional view (Supplementary material Fig. S1) of the interior of the scaffold. The channels in the scaffold have an elliptical cross-sectional profile, as the round PVA filament is flattened during printing of the mould, and the distance between two rows of structured pores is about $800 \mu \mathrm{m}$. The dimensions of the pores (width $344 \mu \mathrm{m}$, height $190 \mu \mathrm{m}$ ) are slightly smaller than that of the filaments in the printed mould ( $400 \mu \mathrm{m} \times 200 \mu \mathrm{m}$ ), due to shrinkage during curing of the PDMS elastomer. A random pore region can be seen in the area between two rows of structured pores (blue dotted line). To demonstrate the possibility of controlling the size of the random pores, the previously described PVA mould was filled with smaller salt or sugar crystals, yielding scaffolds shown in the Supplementary material Fig. S4 (using 20-40 $\mu \mathrm{m}$ salt crystals) and Fig. S5 (using 100-200 $\mu \mathrm{m}$ sugar crystals). The SEM images with 

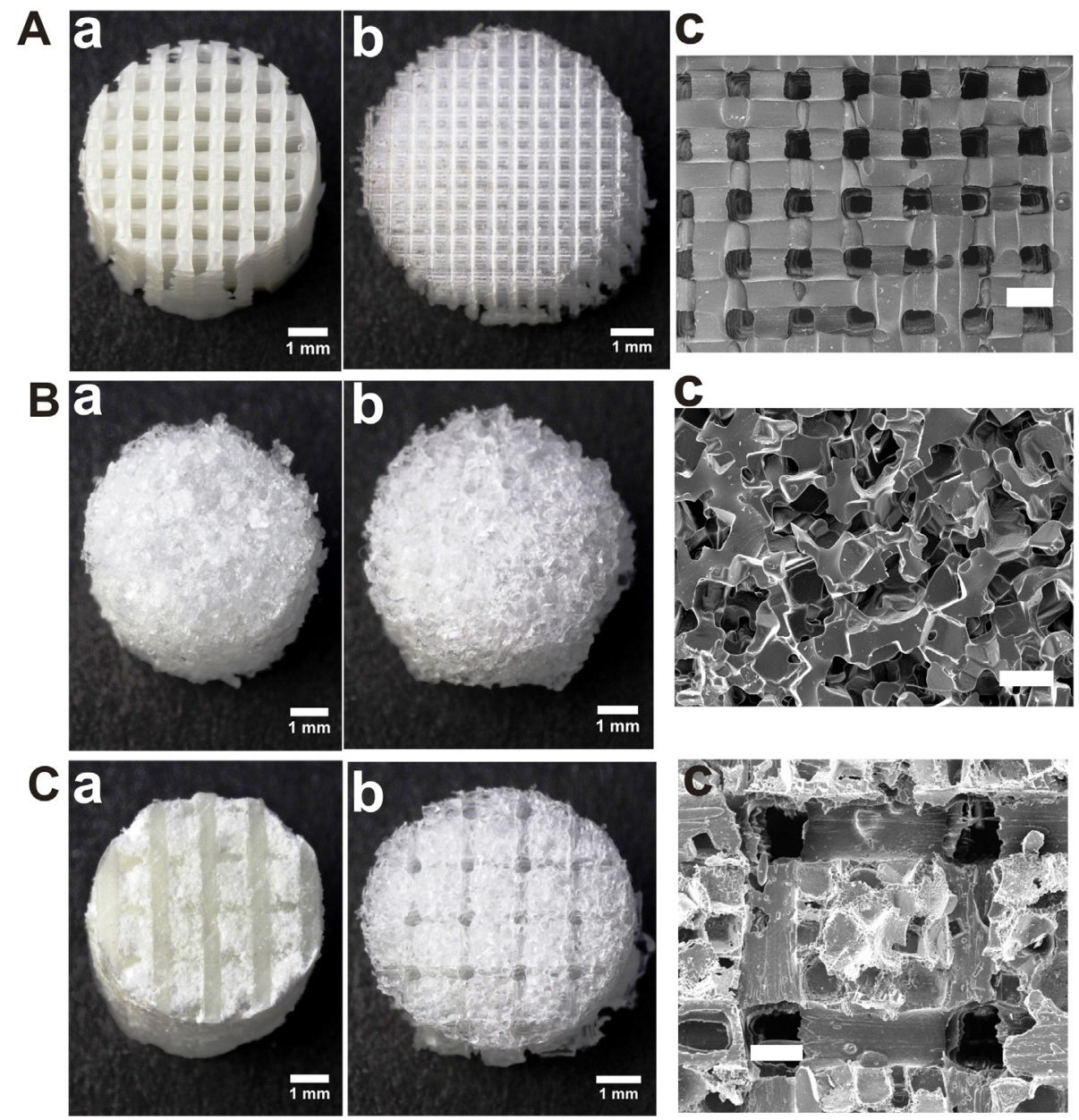

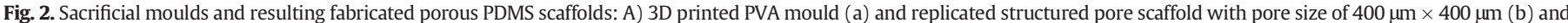

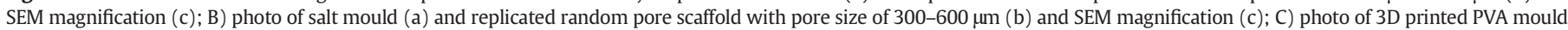

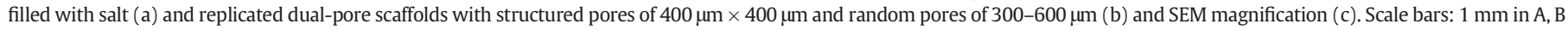
and $\mathrm{C}(\mathrm{a} \& \mathrm{~b}) ; 400 \mu \mathrm{m}$ in $\mathrm{A}, \mathrm{B}$ and $\mathrm{C}(\mathrm{c})$.

different magnifications in Fig. S4 clearly show the highly interconnected small random pores (20-50 $\mu \mathrm{m})$ along with the $400 \mu \mathrm{m} \times 400 \mu \mathrm{m}$ structured pores. The inter-filament distance of a PVA mould has to be optimized according to the size of the salt or sugar crystals needed to generate the random pores. Using different size of porous mesh, it is possible to obtain salt or sugar crystals with different size distribution. If large crystals need to be used, the distance between the deposited PVA filaments has to be increased by reducing the porosity of PVA mould from $40 \%$ infill to lower.

Here, we have shown the fabrication of dual pore scaffolds with dimensions of $25 \mathrm{~mm} \times 25 \mathrm{~mm} \times 10 \mathrm{~mm}$ (length $\times$ width $\times$ height). However, the scalability of the PVA mould printing and the scaffold casting process that we have demonstrated in our previous work [25], mean that the method proposed in this paper can generate dual-pore scaffolds with dimension relevant for the size required for creating artificial organs. We used the biocompatible and non-biodegradable elastomeric PDMS, which is widely used in biological and medical applications [28, 29], to demonstrate the ease of fabrication to obtain different porous scaffolds for tissue engineering applications. It has already been shown that PDMS scaffolds have the potential to support long-term growth of liver cells [25]. However, this method can also be applied to other materials, providing the possibility to fine-tune the properties of bulk scaffold by choosing a suitable biomaterial. To demonstrate this, poly ( $\epsilon$-caprolactone) (PCL), a FDA approved biodegradable polymer [30], was used to fabricate dual-pore PCL scaffolds (Supplementary material Fig. S5).
Here, we have shown the biocompatibility and functionality of HepG2 cells supported by various silicone scaffolds (Figs. 5-7) however this has to be tested with the type cells required to engineer the relevant tissue. Silicone based non-degradable scaffolds could be utilized to develop life support system (LSS) such as an extracorporeal liver [31] for the short term treatment of patients with liver failure. Utilizing silicone based highly porous scaffolds for extracorporeal liver device offers several benefits such as easy fabrication of scaffold structures with dual pores, structurally strong and elastic material for building large scale porous structures, easy sterilization method by autoclavation and without any shrinking or swelling properties allows robust fluidic perfusion into the scaffolds compared to some hydrogels [25]. Furthermore, FDA approved medical grade silicone elastomers are available, which should be compatible with the described fabrication method.

\subsection{Scaffold characterization}

3.2.1. Removal of the sacrificial materials (salt and PVA) from the scaffolds

FTIR spectroscopy was used to monitor the complete removal of the sacrificial materials (salt and PVA) from the scaffolds. Fig. 4A shows FTIR spectra of salt crystals (black), cross-linked PDMS (blue), 3D printed PVA filament (red) and PDMS dual-pore scaffold after removal of salt and PVA (green). In the spectrum for PVA, peaks were observed at $3400 \mathrm{~cm}^{-1}(-\mathrm{OH})$ and $1740 \mathrm{~cm}^{-1}(\mathrm{CO})$, whereas salt crystals had a peak at $3400 \mathrm{~cm}^{-1}(-\mathrm{OH})$. All of these peaks were absent in spectrum for cross-linked PDMS due to the different molecular structure [32,33]. 

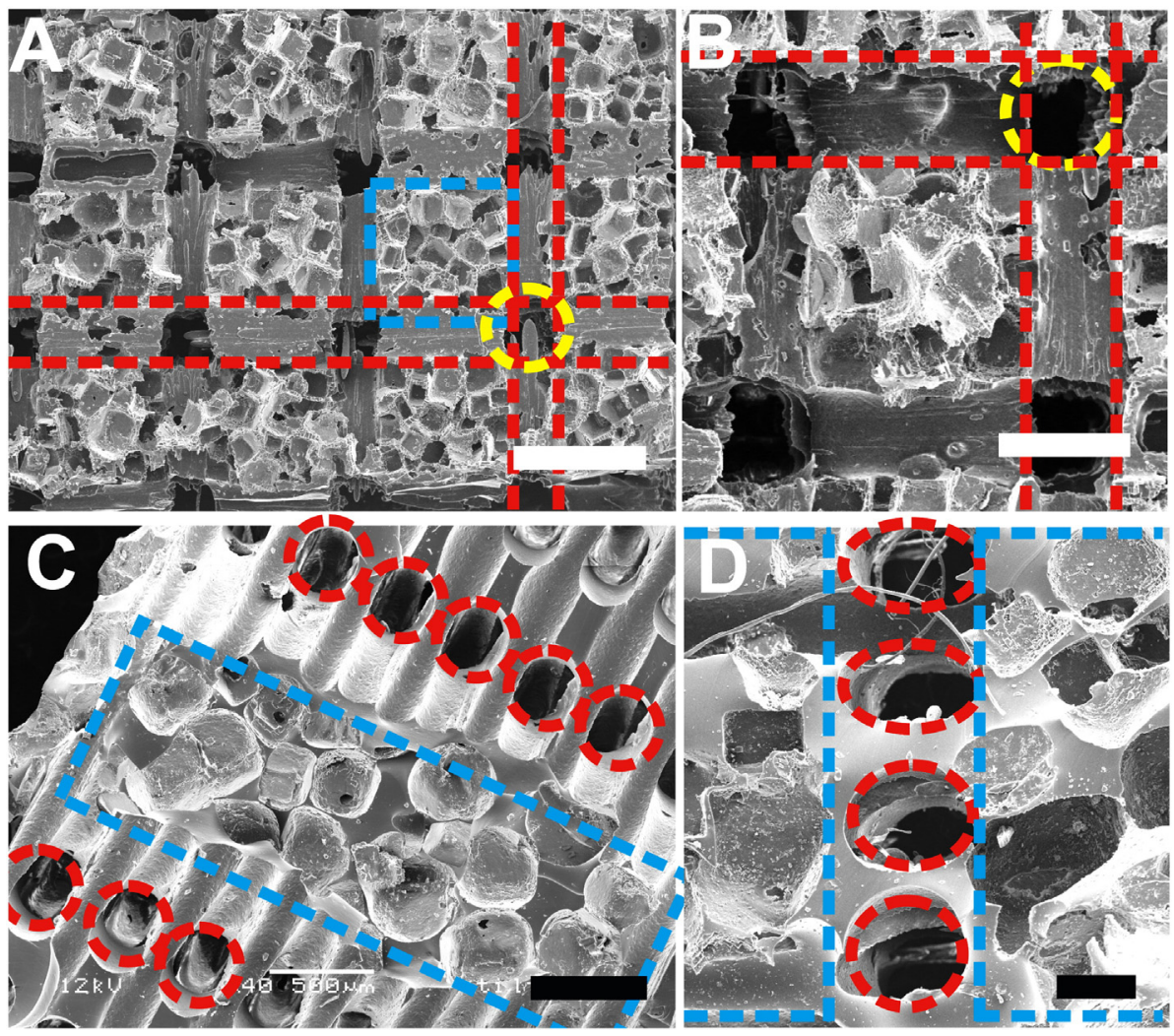

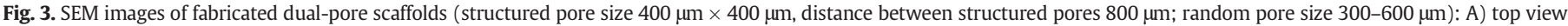

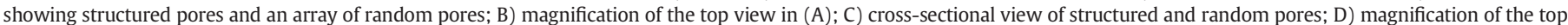

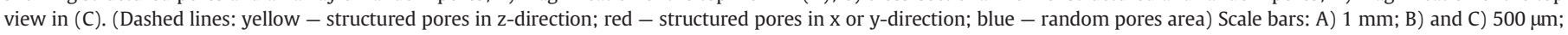
D) $250 \mu \mathrm{m}$. (For interpretation of the references to colour in this figure legend, the reader is referred to the web version of this article.)

The spectrum for the fabricated 3D scaffold (recorded from the interior regions as shown in the Supplementary Fig. S1) completely resembles the one recorded for cross-linked PDMS, which clearly indicated that PVA and salts had been completely removed from the structure. Spectra were recorded from at least six different positions throughout the final scaffold to obtain a complete confirmation. Simultaneously, a basic

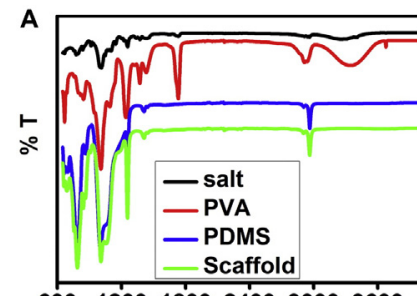

60012001800240030003600

Wavenumber $\left(\mathrm{cm}^{-1}\right)$
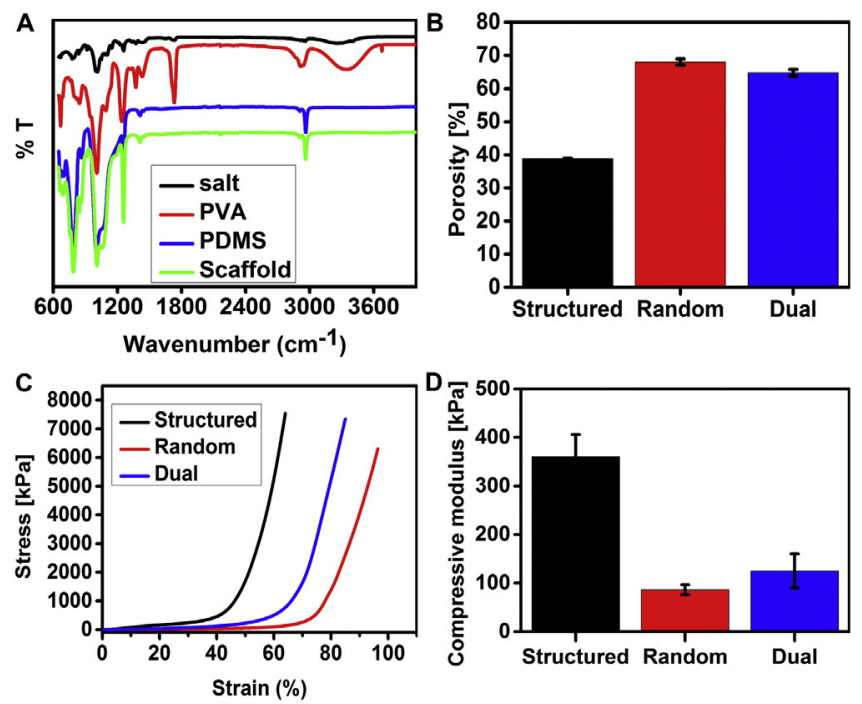

Fig. 4. A) FTIR spectra: salt crystals (black), cross-linked PDMS (blue), 3D printed PVA filament (red), and dual-pore PDMS scaffold after removal of salt and PVA (green). Mechanical characteristics of different scaffolds: B) porosity; C) stress-strain curves at $4 \mathrm{~N}$ load; D) compressive modulus. (For interpretation of the references to colour in this figure legend, the reader is referred to the web version of this article.) visualization of the PVA removal was done. The PVA-salt-PDMS structures were transferred into a water beaker with a magnetic stirrer to aid the faster dissolution of the PVA and salt. Initially, when immersing the PVA-salt-PDMS structures into water, they sank to the bottom of the container. After complete removal of PVA and salt, the hydrophobic PDMS scaffold structures were floating on the surface. During the process of dissolution the water turned cloudy due to the release of PVA into the water, and water were replaced until it remained clear.

\subsubsection{Porosity}

The degree of porosity and pore size of the scaffold material both at the macroscopic and the microscopic level play a very important role in tissue regeneration [34]. The total porosity of the scaffolds, fabricated with the three different porous geometries was determined experimentally and presented in Fig. 4B. The porosity of the dual-pore scaffold was $64.8 \pm 1.05 \%$ whereas in case of structured and random pore scaffolds the porosity was $39.5 \pm 0.08 \%$ and $68.02 \pm 0.95 \%$, respectively. The porosity of the dual-pore scaffolds was higher compared to the structured pore scaffolds due to the presence of both structured and random pores. Previously, we have shown the possibilities to fabricate structured pore PDMS scaffolds with porosities ranging from $20 \%$ to $80 \%$ by varying the infill of the printed PVA mould from $20 \%$ to $80 \%$. In this study, dual-pore scaffolds were fabricated using $40 \%$ infill PVA moulds. For better comparison, the physical characterization of dual-pore scaffolds is compared with the structured pore scaffolds generated using 40\% infill PVA moulds. Previously published dual-pore fabrication methods have shown similar behaviour in terms of porosity, the total porosity of dual-pore scaffolds being always greater than the porosity of structured and random pore scaffolds $[12,16]$. In this study, the random pore scaffolds showed higher porosity (68.02\%) than the dual-pore scaffolds due to the larger size of the random pores in comparison with the size of the structured pores (Fig. 3). To achieve higher porosity in dual-pore 
scaffolds in comparison to random pore scaffolds, the size of the random pores has to be smaller than the structured pores. This concept was illustrated in the Supplementary material Figs. S4 and S5 where porosity of about $80 \%$ was achieved. The porosities of dual-pore scaffolds completely depend on the microstructure of 3D printed PVA mould and the size of the salt crystals filled in it. Hence, a desired range of pore dimensions can easily be optimized through this fabrication technique.

\subsubsection{Mechanical testing}

The mechanical properties of tissue engineering scaffolds can modulate cell morphology, proliferation, migration and differentiation [35-37], and it is therefore important to control the mechanical properties of the bulk scaffold while engineering an artificial tissue. Mechanical compression tests were conducted with dry scaffolds with the different pore structures. Fig. 4C shows typical stress-strain curves of the different scaffolds at a constant compression rate of $0.5 \mathrm{~mm} \mathrm{~min}^{-1}$. The compressive modulus of structured, random and dual-pore scaffolds was determined to be $359 \pm 16,84 \pm 10$ and $125 \pm 35 \mathrm{kPa}$, respectively (Fig. 4D). Previously, it has been shown that the compressive modulus of porous scaffolds reduces significantly as the porosity of the scaffolds increases $[25,38,39]$. For the same reason, the dual-pore scaffolds showed intermediate mechanical properties compared to structured and random pore scaffolds, indicating the expected relationship between porosity and the mechanical stiffness of the scaffolds. The compressive modulus of the structured pore scaffolds was similar to our previous study presented with similar kind of scaffolds (about $360 \mathrm{kPa}$ ) [25]. Moreover, our mechanical tests on the different scaffolds showed similar trend as previously reported for structured, random and dual-pore scaffolds fabricated of PCL $[12,16]$. The result of the mechanical test indicates that the mechanical properties of the dual-pore scaffolds can be easily modified by the combination of random and structured pores. Since the elastic moduli of human organs and tissues are very diverse, the stiffness of fabricated dual-pore PDMS scaffolds can be tuned by changing the porosity of the scaffolds or the degree of cross-linking, i.e. the ratio between the PDMS base and the curing agent [36]. As mentioned above, the fabrication technique presented in this paper can be applied to other materials than PDMS, such as the biomaterial PCL (Supplementary material Fig. S5), which provides an additional route for fine-tuning scaffold stiffness according to the requirements of in vivo tissues.

\subsection{Cell proliferation and viability}

Although the proposed dual-pore scaffold fabrication technique can be used to control the physical and mechanical properties of the scaffolds, it is important to evaluate the cell behaviour in the scaffold architecture. As PDMS is a hydrophobic material, it is important to render the scaffold surfaces hydrophilic before seeding cells into the scaffolds. To achieve this, all the scaffolds were treated with oxygen plasma. The achieved hydrophilicity was confirmed by the decrease in contact angle from $120^{\circ} \pm 4^{\circ}$ to below $10^{\circ}$.

\subsubsection{Biochemical assays of cell proliferation and functionality}

Proliferation and functionality of HepG2 cells in the different porous scaffolds was monitored during 16 days (Fig. 5). The proliferation of HepG2 cells within the scaffolds was determined based on both the total intra cellular DNA content using the Picogreen assay and cellular metabolic activity using alamarBlue ${ }^{\circledR}$ assay. Along with cellular proliferation, the functionality of HepG2 cells was determined based on the extracellular albumin release as a liver-specific marker.

As shown in Fig. 5A, from day 2 to day 4, the total cell number increased (proliferated) slowly in all three types of scaffolds, whereas after day 4 onwards the proliferation rate increased especially in the random and dual-pore scaffolds where the cell numbers increased at similar rates. However, from day 9 the cellular proliferation rate in the dual-pore scaffolds was higher in comparison to the two other types

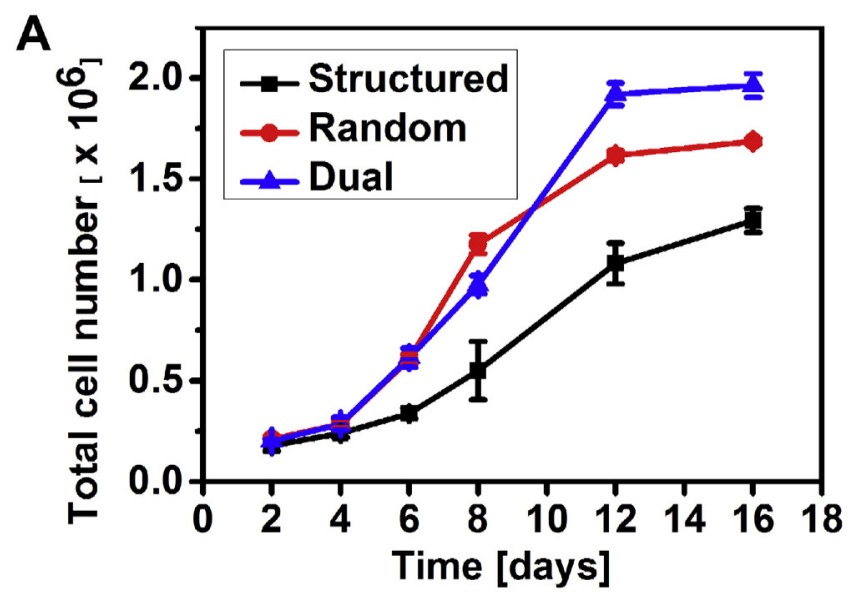

B

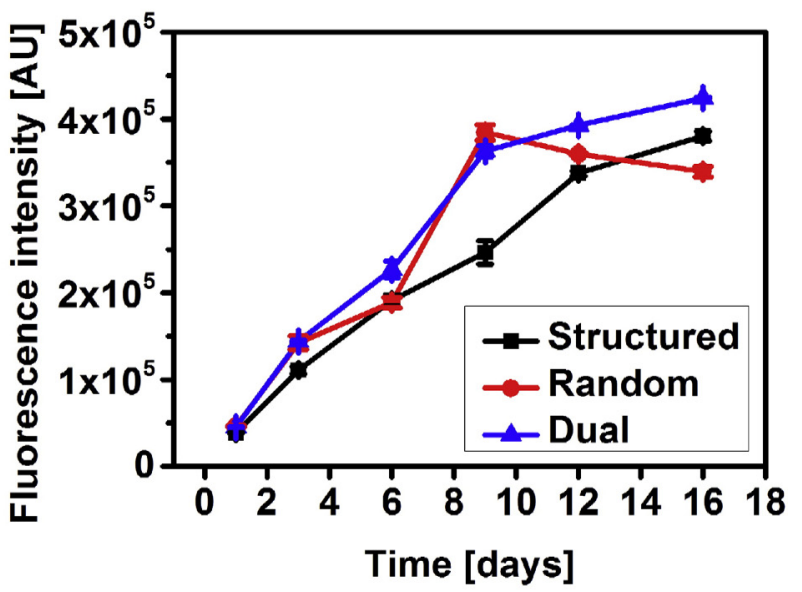

C

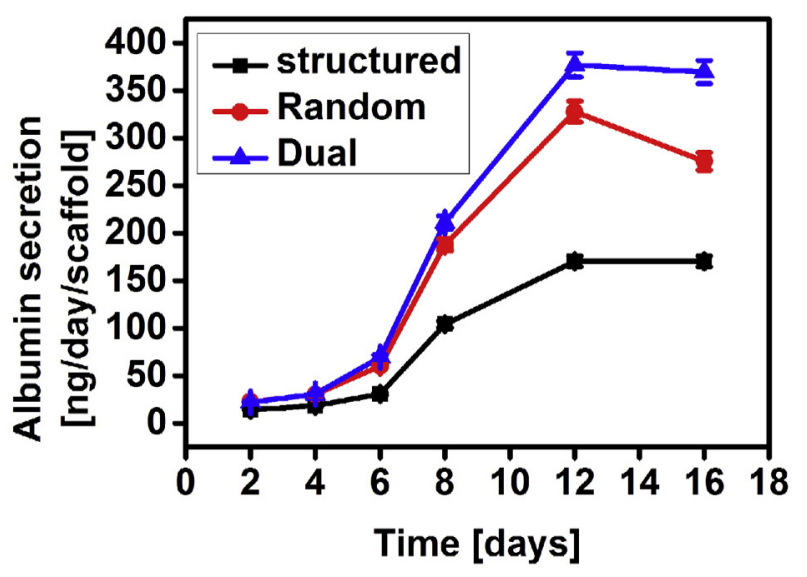

Fig. 5. HepG2 cell proliferation and functionality on different scaffolds: A) total cell number (Picogreen assay) during day 2-16 (B). B) Metabolic activity (alamarBlue ${ }^{\circledR}$ assay) over 116 days (D). C) Albumin secretion over 16 days (F). Data represents mean \pm s.e.m. $(n=6)$.

of scaffolds. From day 12 the number of cells reached a steady state in both random and dual pore scaffolds whereas the number of cells continued to increase in the structured pore scaffolds. At the same time the number of cells was lower in the structured pore scaffolds throughout the culture period in comparison with the random and the dual-pore scaffolds.

Along with cell proliferation the metabolic activity of HepG2 cells in the three different types of scaffolds was determined using the alamarBlue ${ }^{\circledR}$ assay (Fig. 5B). From day 1 to day 9 , the metabolic activity increased steadily in all the different types of scaffolds (Fig. 5B) although the activity was lower in the structured pores scaffolds. Until day 9, the cells grown in the random pore and dual-pore scaffolds did not show 
any significant difference. However, after day 9, the metabolic activity in the random pore scaffolds started to decline whereas in dual- and structured pore scaffolds continued to increase until the end of the experiment.

Fig. 5C shows the magnitude of albumin secretion from HepG2 cells cultured in the different types of scaffolds. Similar to the cell proliferation profiles (Fig. 5A), albumin production from HepG2 cells grown in all of the three different types of scaffolds increased for the first 12 days (Fig. 5C). On day 12, the cells cultured in the dual-pore scaffolds produced the highest amount of albumin (375 ng/day/scaffold) compared to the cells cultured in the random and structured pore scaffolds (325 and $145 \mathrm{ng} /$ day/scaffold, respectively). However from day 12 to 16 , the albumin secretion rate from cells in random scaffolds started to decline, whereas the rate remained constant for the cells grown in both the dual-pore and structured pore scaffolds.

Both the random and dual pore scaffolds contain random pores, which increase the surface area compared to structured pore scaffolds. Therefore more cells could be trapped and adhere on these scaffolds and there were also more surface for cell proliferation. In the literature, it has been shown that SFF fabricated structured pore scaffolds have lower cell adherence after seeding in comparison with random and dual-pore scaffolds [12,16], which clearly agrees with our result. From day 1 until day 9, the cells grown in random pores scaffolds or in the dual-pore scaffolds did not show any significant difference in cell proliferation, metabolic activity and albumin secretion, whereas these parameters were considerable lower for the structured pores scaffolds, probably due to smaller surface area. The declining metabolic activity from day 9 or in albumin secretion from day 12 in the random pore scaffolds may be explained by insufficient nutrient and oxygen supply into the scaffold or by accumulation of cellular waste, due to limited mass transport in this type of scaffold. In summary, the results clearly indicate that the cell proliferation, metabolic activity and albumin secretion from cells growing in the dual-pore scaffolds showed better performance compared to the cells in the structured and random pore scaffolds due to high surface area of the random pores in combination with better nutrient and oxygen supply as well as waste removal through the structured pores.

\subsubsection{Cell distribution and viability within the scaffolds}

To visualize cell distribution and viability, in the different porous scaffolds, qualitative live/dead staining was carried out on day 2, 8 and 16 after cell seeding (Fig. 6). On day 2, the number of live cells distributed on the surface of the random (Fig. 6Ba) and dual-pore scaffolds (Fig. 6Ca) was higher compared to that on the structured pore scaffolds (Fig. 6Aa), which correlates well with the biochemical assays shown in Fig. 5. From day 2 to day 16, cells grow uniformly on the surface of all the different types of scaffolds (Fig. 6Ab, c and d; Bb, c and d; Cb, c and d). However on day 16 , more dead cells could be observed on the surface of the random pore scaffolds (Fig. 6Bd), whereas on the surface of the structured (Fig. 6Ad) and dual-pore (Fig. 6Cd) scaffolds only very few dead cells could be observed. In dual-pore scaffolds, cell distribution was characterized by initial (from day 2 to 8 ) cell growth primarily in the structured pore regions (Fig. 6Ca and b). Later, when all the structured pores regions were completely covered, the cells migrated into the random pore regions of the scaffold as shown for day 16 (Fig. 6Cc).

In Fig. 6, it was not possible to see the cell distribution in the central parts of the scaffolds, which are more critical due to the limitation of nutrient and oxygen supply. Therefore, the scaffolds were cut longitudinally through the centre (Supplementary material Fig. S1) and live/dead stained to visualize the cell distribution inside the scaffolds (Fig. 7). The cells were distributed more uniformly inside the structured (Fig. 7A) and dual-pore (Fig. 7C) scaffolds than inside the random pore scaffolds (Fig. 7B). On day 2, the cell distribution inside the different scaffolds was very low (Fig. 7Aa, Ba, Ca) but over time, the cell density in the structured and dual-pore scaffolds steadily increased (Fig. 7Aa-c, Cac). On day 16, the structured (Fig. 7Ac) and dual-pore (Fig. 7Cc) scaffolds showed uniform cell distribution throughout, whereas the random pore scaffolds (Fig. 7Bc) had very low amount of cells distributed in the central regions. For this type of scaffold the cells appeared to be mainly proliferating on the outer surface, where there is direct contact with the culture medium, instead of migrating into the centre of the scaffold. This difference in cell distribution can be explained by the presence of the structured pores that provide interconnections in $\mathrm{x}, \mathrm{y}$ and $\mathrm{z}$-direction throughout the structured and dual-pore scaffolds. Previously, similar kind of results has been reported, indicating that SFF fabricated scaffolds

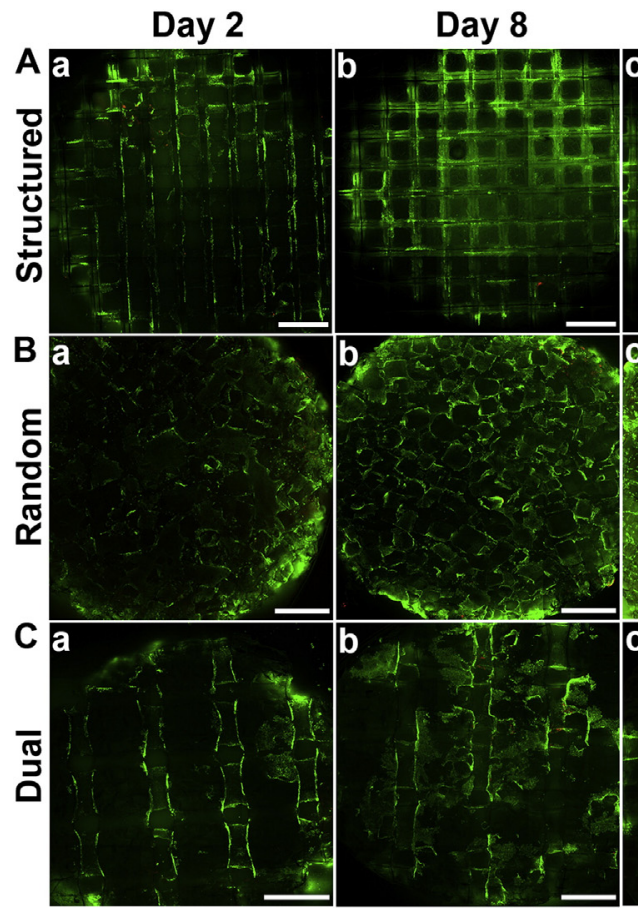

Day 16

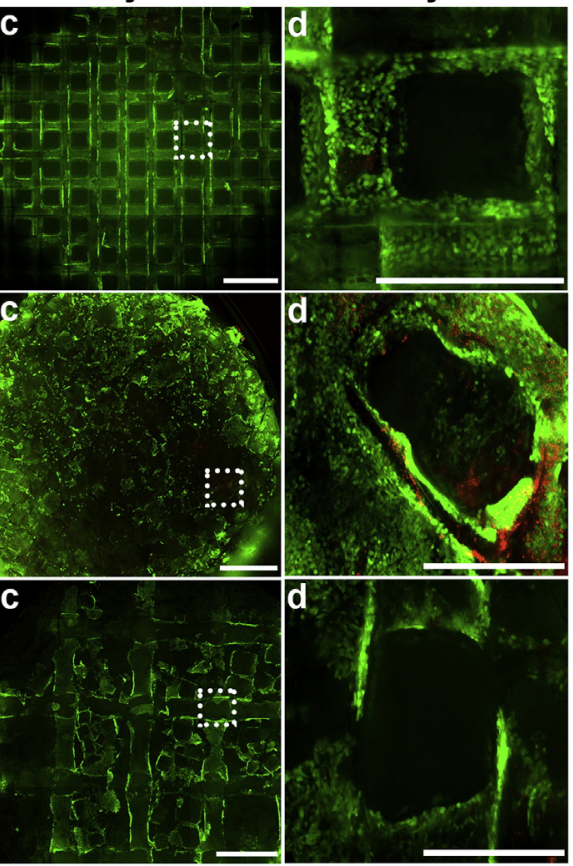

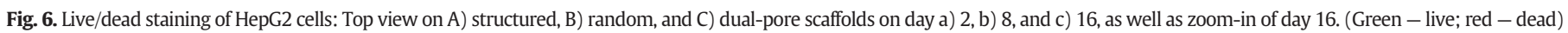
Scale bars: A, B \& C (a, b, c) 1 mm; A, B, C (d) $350 \mu \mathrm{m}$. (For interpretation of the references to colour in this figure legend, the reader is referred to the web version of this article.) 


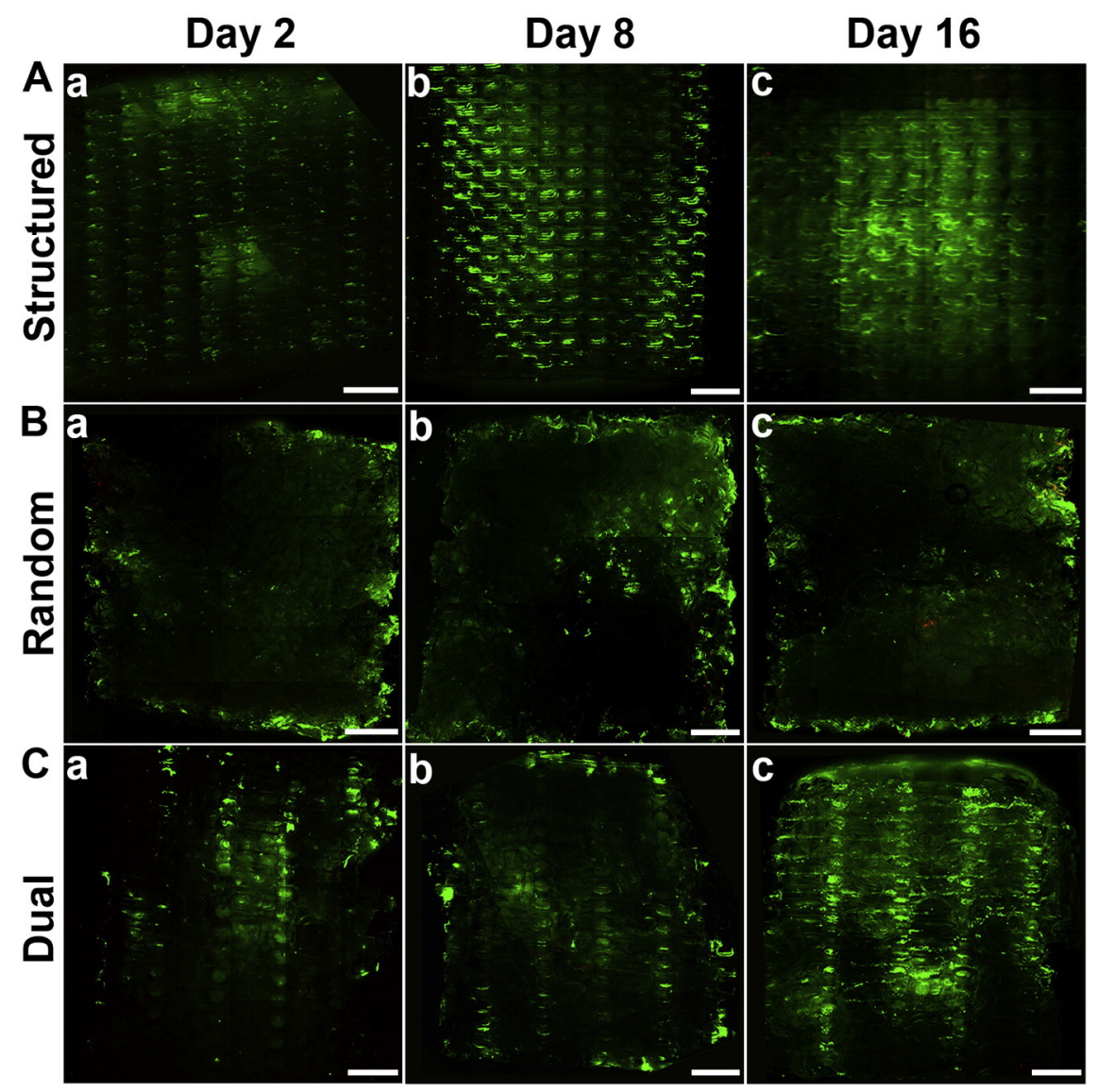

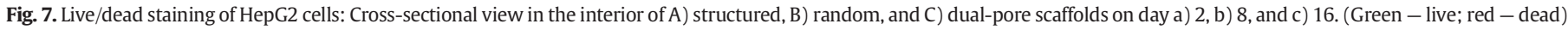
Scale bar: $1 \mathrm{~mm}$.

had more uniform cell distribution and penetration of cells into the scaffolds $[16,25,40]$. Moreover, more dead cells appeared over time inside the random pore scaffolds (Fig. 7Ba, b and c), which completely agrees with the biochemical assay that showed first a drop in metabolic activity (Fig. 5B) and later in the albumin secretion (Fig. 5C) from the cells grown in random pores scaffolds. Zhang et al. have reported a similar phenomenon by creating PCL random pore scaffolds with a combination of different pore dimensions [9]. They also showed that after 14 days of cell culturing, the cell distribution in the random porous scaffolds was always on the outer edges which completely agrees with our result. Homogeneous cell distribution in the bulk scaffold prolongs the proliferation period, gives uniform tissue formation and better cell differentiation characteristics as shown in previous works [40-42]. The dual-pore scaffolds are superior to the two other types of scaffold as it combines high cell number (Fig. 5A), metabolic activity (Fig. 5B), and albumin secretion (Fig. 5C) with uniform distributing of living cells both on (Fig. 6C) and into the scaffolds (Fig. 7C). In future works, the effectiveness of dual-pore scaffolds will be tested for co-culturing of two different populations of cells: liver cells in the random pore region and endothelial cells as a lining of the structured pores.

\section{Conclusions}

We present a method to fabricate dual-pore scaffold by combining 3D filament printing of water soluble PVA sacrificial mould for primary structured pores and salt leaching to create random pores within the bulk scaffold. The method provides control over pore geometry and dimensions as well as mechanical stiffness of both the structured and random pores of the dual-pore scaffold. Using PDMS as the scaffold material, we have demonstrated that the fabrication process is rapid and inexpensive as well as scalable for generation of scaffolds of a size, relevant for thick tissues. The PVA printed sacrificial moulds can also be used with different biodegradable natural polymers (e.g. gelatine and silk) combined with freeze-drying, to provide scaffolds with wide range of mechanical properties. Human hepatoblastoma (HepG2) cells were grown in different types of scaffold for 16 days monitored with respect to attachment, distribution, proliferation, viability, metabolic activity, and albumin secretion and cells grown in dual-pore scaffolds with cells grown in only structured or only random pores scaffold. The dual-pore scaffolds with highly interconnected structured pores combined with the adjacent random pores was superior to the two other types of scaffold as it combines high cell number, metabolic activity, and albumin secretion with uniform distributing of living cells in the entire volume of the scaffold. In conclusion, the described fabrication technique is rapid, inexpensive, scalable, and compatible with different polymers, making it suitable for engineering various large scale organs/ tissues.

\section{Acknowledgements}

This work has been financially supported by EU project NanoBio4Trans ("A new nanotechnology-based paradigm for engineering vascularised liver tissue for transplantation", grant no: 304842). We thank Professor Dang Duong Bang for correcting the manuscript and Jesper Scheel for taking photographs of the scaffolds.

\section{Appendix A. Supplementary data}

Supplementary data to this article can be found online at http://dx. doi.org/10.1016/j.msec.2015.12.032. 


\section{References}

[1] K.C. Rustad, M. Sorkin, B. Levi, M.T. Longaker, G.C. Gurtner, Strategies for organ leve tissue engineering, Organogenesis 6 (2010) 151-157.

[2] A. Khademhosseini, J.P. Vacanti, R. Langer, Progress in tissue engineering, Sci. Am. (2009).

[3] L.S. Wray, J. Rnjak-Kovacina, B.B. Mandal, D.F. Schmidt, E.S. Gil, D.L. Kaplan, A silk-based scaffold platform with tunable architecture for engineering critically-sized tissue constructs, Biomaterials 33 (2012) 9214-9224.

[4] S. Chung, M.W. King, Design concepts and strategies for tissue engineering scaffolds, Biotechnol. Appl. Biochem. 58 (2008) 423-438.

[5] S.J. Hollister, Scaffold design and manufacturing: from concept to clinic, Adv. Mater. 21 (2009) 3330-3342.

[6] M.E. Kolewe, H. Park, C. Gray, X. Ye, R. Langer, L.E. Freed, 3D structural patterns in scalable, elastomeric scaffolds guide engineered tissue architecture, Adv. Mater. 25 (2013) 4459-4465.

[7] B. Derby, Printing and prototyping of tissues and scaffolds, Science 338 (2012) 921-926.

[8] M. Lee, J.C.Y. Dunn, B.M. Wu, Scaffold fabrication by indirect three-dimensional printing, Biomaterials 26 (2005) 4281-4289.

[9] Q. Zhang, H. Luo, Y. Zhang, Y. Zhou, Z. Ye, W. Tan, M. Lang, Fabrication of threedimensional poly( $\varepsilon$-caprolactone) scaffolds with hierarchical pore structures for tissue engineering, Mater. Sci. Eng. C. Mater. Biol. Appl. 33 (2013) 2094-2103.

[10] S. Park, G. Kim, Y.C. Jeon, Y. Koh, W. Kim, 3D polycaprolactone scaffolds with controlled pore structure using a rapid prototyping system, J. Mater. Sci. Mater. Med. 20 (2009) 229-234.

[11] H.W. Kang, J.W. Rhie, D.W. Cho, Development of a bi-pore scaffold using indirect solid freeform fabrication based on microstereolithography technology, Microelectron. Eng. 86 (2009) 941-944.

[12] Y.S. Cho, M.W. Hong, Y.Y. Kim, Y.-S. Cho, Assessment of cell proliferation in salt-leaching using powder (SLUP) scaffolds with penetrated macro-pores, J. Appl. Polym. Sci. 131 (2014) 40240-40248.

[13] B. Dorj, J.H. Park, H.W. Kim, Robocasting chitosan/nanobioactive glass dual-pore structured scaffolds for bone engineering, Mater. Lett. 73 (2012) 119-122.

[14] K. Park, H. Jung, J.S. Son, K.D. Park, J.J. Kim, K.D. Ahn, D.K. Han, Preparation of biodegradable polymer scaffolds with dual pore system for tissue regeneration, Macromol. Symp. 249-250 (2007) 145-150.

[15] S.H. Park, T.G. Kim, H.C. Kim, D.Y. Yang, T.G. Park, Development of dual scale scaffolds via direct polymer melt deposition and electrospinning for applications in tissue regeneration, Acta Biomater. 4 (2008) 1198-1207.

[16] Y. Sang, M. Wha, S. Kim, S. Lee, J. Hee, Y. Yul, Y. Cho, Fabrication of dual-pore scaffolds using SLUP (salt leaching using powder) and WNM (wire-network molding) techniques, Mater. Sci. Eng. C 45 (2014) 546-555.

[17] W. Zhang, L.S. Wray, J. Rnjak-Kovacina, L. Xu, D. Zou, S. Wang, M. Zhang, J. Dong, G Li, D.L. Kaplan, X. Jiang, Vascularization of hollow channel-modified porous silk scaffolds with endothelial cells for tissue regeneration, Biomaterials 56 (2015) 68-77.

[18] J. Woo Jung, H.-G. Yi, T.-Y. Kang, W.-J. Yong, S. Jin, W.-S. Yun, D.-W. Cho, Evaluation of the effective diffusivity of a freeform fabricated scaffold using computational simulation, J. Biomech. Eng. 135 (2013) 84501.

[19] J. Peña, J. Román, M. Victoria Cabañas, M. Vallet-Regí, An alternative technique to shape scaffolds with hierarchical porosity at physiological temperature, Acta Biomater. 6 (2010) 1288-1296.

[20] M. Zhu, K. Wang, J. Mei, C. Li, J. Zhang, W. Zheng, D. An, N. Xiao, Q. Zhao, D. Kong, L. Wang, Fabrication of highly interconnected porous silk fibroin scaffolds for potential use as vascular grafts, Acta Biomater. 10 (2014) 2014-2023.

[21] B. Farkas, I. Romano, L. Ceseracciu, A. Diaspro, F. Brandi, S. Beke, Four-order stiffness variation of laser-fabricated photopolymer biodegradable scaffolds by laser parameter modulation, Mater. Sci. Eng. C 55 (2015) 14-21.
[22] A. Díaz Lantada, H. Alarcón Iniesta, B. Pareja Sánchez, J.P. García-Ruíz, Free-form rapid prototyped porous PDMS scaffolds incorporating growth factors promote chondrogenesis, Adv. Mater. Sci. Eng. 2014 (2014).

[23] E.M. Jeffries, S. Nakamura, K.-W. Lee, J. Clampffer, H. Ijima, Y. Wang, Micropatterning electrospun scaffolds to create intrinsic vascular networks, Macromol. Biosci. 14 (2014) 1514-1520.

[24] I. Ortega, L. Dew, A.G. Kelly, C.K. Chong, S. MacNeil, F. Claeyssens, Fabrication of biodegradable synthetic perfusable vascular networks via a combination of electrospinning and robocasting, Biomater. Sci. (2015) 592-596.

[25] S. Mohanty, L.B. Larsen, J. Trifol, P. Szabo, H.V.R. Burri, C. Canali, M. Dufva, J. Emnéus, A. Wolff, Fabrication of scalable and structured tissue engineering scaffolds using water dissolvable sacrificial 3D printed moulds, Mater. Sci. Eng. C 55 (2015) 569-578.

[26] B.B. Mandal, A. Grinberg, E. Seok Gil, B. Panilaitis, D.L. Kaplan, From the cover: highstrength silk protein scaffolds for bone repair, Proc. Natl. Acad. Sci. 109 (2012) 7699-7704.

[27] S.J. Choi, T.H. Kwon, H. Im, D.I. Moon, D.J. Baek, M.L. Seol, J.P. Duarte, Y.K. Choi, A polydimethylsiloxane (PDMS) sponge for the selective absorption of oil from water, ACS Appl. Mater. Interfaces 3 (2011) 4552-4556.

[28] A. Khademhosseini, R. Langer, J. Borenstein, J.P. Vacanti, Microscale technologies for tissue engineering and biology, Proc. Natl. Acad. Sci. U. S. A. 103 (2006) 2480-2487.

[29] E. Berthier, E.W.K. Young, D. Beebe, Engineers are from PDMS-land, Biologists are from Polystyrenia, Lab Chip 12 (2012) 1224-1237.

[30] H. Lee, S. Ahn, L.J. Bonassar, W. Chun, G. Kim, Cell-laden poly( $\varepsilon$-caprolactone)/alginate hybrid scaffolds fabricated by an aerosol cross-linking process for obtaining homogeneous cell distribution: fabrication, seeding efficiency, and cell proliferation and distribution, Tissue Eng. Part C Methods 19 (2013) 784-793.

[31] A.J. Strain, J.M. Neuberger, A bioartificial liver-state of the art, Science 295 (2002) 1005-1009.

[32] X. Xiong, Z. Wu, J. Pan, L. Xue, Y, Xu, H. Chen, A facile approach to modify poly(dimethylsiloxane) surfaces via visible light-induced grafting polymerization, J. Mater. Chem. B 3 (2015) 629-634.

[33] F. Zhao, X. Wang, B. Ding, J. Lin, J. Hu, Y. Si, J. Yu, G. Sun, Nanoparticle decorated fibrous silica membranes exhibiting biomimetic superhydrophobicity and highly flexible properties, RSC Adv. 1 (2011) 1482.

[34] V. Karageorgiou, D. Kaplan, Porosity of 3D biomaterial scaffolds and osteogenesis, Biomaterials 26 (2005) 5474-5491.

[35] G. Chen, C. Dong, L. Yang, Y. Lv, 3D scaffolds with different stiffness but the same microstructure for bone tissue engineering, ACS Appl. Mater. Interfaces 7 (2015) 15790-15802

[36] B. Trappmann, J.E. Gautrot, J.T. Connelly, D.G.T. Strange, Y. Li, M.L. Oyen, M.A. Cohen Stuart, H. Boehm, B. Li, V. Vogel, J.P. Spatz, F.M. Watt, W.T.S. Huck, Extracellularmatrix tethering regulates stem-cell fate, Nat. Mater. 11 (2012) 642-649.

[37] T. Yeung, P.C. Georges, L.A. Flanagan, B. Marg, M. Ortiz, M. Funaki, N. Zahir, W. Ming, V. Weaver, P.A. Janmey, Effects of substrate stiffness on cell morphology, cytoskeletal structure, and adhesion, Cell Motil. Cytoskeleton 60 (2005) 24-34.

[38] Y.S. Cho, B.S. Kim, H.K. You, Y.S. Cho, A novel technique for scaffold fabrication: SLUP (salt leaching using powder), Curr. Appl. Phys. 14 (2014) 371-377.

[39] S. Ahn, Y. Kim, H. Lee, G. Kim, A new hybrid scaffold constructed of solid freeformfabricated PCL struts and collagen struts for bone tissue regeneration: fabrication, mechanical properties, and cellular activity, J. Mater. Chem. 22 (2012) 15901.

[40] J.M. Sobral, S.G. Caridade, R.A. Sousa, J.F. Mano, R.L. Reis, Three-dimensional plotted scaffolds with controlled pore size gradients: effect of scaffold geometry on mechanical performance and cell seeding efficiency, Acta Biomater. 7 (2011) 1009-1018.

[41] Y. Li, T. Ma, D.A. Kniss, L.C. Lasky, S.T. Yang, Effects of filtration seeding on cell density, spatial distribution, and proliferation in nonwoven fibrous matrices, Biotechnol. Prog. 17 (2001) 935-944.

[42] C.E. Holy, M.S. Shoichet, J.E. Davies, Engineering three-dimensional bone tissue in vitro using biodegradable scaffolds: Investigating initial cell-seeding density and culture period, J. Biomed. Mater. Res. 51 (2000) 376-382. 